\title{
Introduction to Special Section: Advancing the Field of Vocational Rehabilitation with the International Classification of Functioning, Disability and Health (ICF)
}

\author{
Reuben Escorpizo • Hans Peter Gmünder • \\ Gerold Stucki
}

Published online: 21 April 2011

(C) Springer Science+Business Media, LLC 2011

\begin{abstract}
Background Work disability is a major burden to individuals and the society. To mitigate this burden, vocational rehabilitation has been at the forefront of facilitating work participation. With the complexity of vocational rehabilitation, we need a unifying framework to capture the essential domains of functioning. The International Classification of Functioning, Disability and Health (ICF) could serve as the common reference and language. The purpose of this special section is to demonstrate the use and benefits of the ICF to stakeholders and advocates of vocational rehabilitation. Methods The project on the ICF Core Set for vocational rehabilitation was conducted in collaboration with national and international organizations. The project consisted of three sequential phases: (1) four development studies, (2) international consensus conference, and (3) testing and validation of the ICF Core Set. Results In the first article, a conceptual definition of vocational rehabilitation based on the ICF is proposed. Findings from the first phase of the project are presented in the following four articles. Our findings reflected a wide
\end{abstract}

R. Escorpizo $(\bowtie) \cdot$ G. Stucki

Swiss Paraplegic Research (SPF),

Guido A. Zäch Str. 4, 6207 Nottwil, Switzerland

e-mail: reuben.escorpizo@paranet.ch

R. Escorpizo - G. Stucki

ICF Research Branch in cooperation with the WHO

Collaborating Centre for the Family of International

Classifications in Germany (at DIMDI), Nottwil, Switzerland

R. Escorpizo · G. Stucki

Department of Health Sciences and Health Policy,

University of Lucerne and SPF, Nottwil, Switzerland

H. P. Gmünder

Swiss Paraplegic Center, (SPZ), Nottwil, Switzerland range of factors that could influence success (or failure) in vocational rehabilitation. Conclusion This special section has presented five articles in an effort to advance our understanding and measurement of vocational rehabilitation process and outcomes. This special section also illustrates the complexity of the contents of vocational rehabilitation and offers the vocational rehabilitation community the added value of integrating the ICF in practice and research.

Keywords ICF · Vocational rehabilitation . Occupational rehabilitation - Employment .

Return to work - Work

\section{Introduction}

“...where a man having had an injury, has admittedly not recovered, returns to work... and then again breaks down, or who still has an obvious physical disability"

-Sir John Collie (1916)

As early as 1916, the topic of return-to-work (RTW) (with important implication to vocational rehabilitation) has been discussed as a major issue affecting workers both at the individual and system level [1]. We all know now about the multi-factorial nature of work disability that goes beyond "physical disability". However, Collie's statement remains relevant and contemporary. Vocational rehabilitation (VR) and RTW strategies which are key components in addressing work disability do involve multi-level and multi-tiered processes [2] which needed to be undertaken in a timely manner.

VR also implies the involvement of multiple stakeholders whose inputs we need to prudently guide us in 
generating ideas, conducting studies, planning intervention, and in developing guidelines. It is also important to note that the burden of work disability is a topic that transcends a wide array of settings (from the clinics, community, and policy arena) which makes work disability a major public health issue. This is one reason why researchers try to understand work disability and how its negative effects can be mitigated. The purpose of this special section on Advancing the field of vocational rehabilitation with the International Classification of Functioning, Disability and Health (ICF) of the Journal of Occupational Rehabilitation (JOOR) is to provide stakeholders and advocates in VR a unifying perspective based on the ICF, a biopsychosocial model developed by the World Health Organization (WHO) [3] and illustrate how the VR community can benefit from using the ICF.

The International Labour Organization (ILO) aims "to promote rights at work, encourage decent employment opportunities, enhance social protection and strengthen dialogue on work-related issues" [4]. With this aim, work issues are put in the forefront of public health. In the context of work disability - work is intertwined with health and health with work. Thus, we need a comprehensive biopsychosocial framework to truly understand the complex and non-linear relationship between work, health, and health-related states. The ICF is a model that we can use to dissect the issues that confront the work-health relationship by providing a common framework for describing functioning domains and contextual factors (e.g. environment). The use of the ICF holds benefits for the VR community at large. According to WHO, the general aim of the ICF is "to provide a unified and standard language and framework for the description of health and health-related states [and permit] communication about health and health care across the world in various disciplines and sciences" [3]. Moreover, the ICF could serve as a tool for issues on public health and rehabilitation such as those pertinent to clinical, health policy, and research [5].

\section{International Acceptance of the ICF}

The ICF has the support of several international organizations such as the International Labour Organization (ILO), the International Society of Physical and Rehabilitation Medicine (ISPRM), the World Confederation for Physical Therapy (WCPT), and the World Federation of Occupational Therapists (WFOT). A report by the ILO cited the ICF as being useful in capturing work disability and statistics [6]. There are other examples supporting the utility of the ICF. Among them is the creation of an interface between the ICF and the WHO Healthy Workplace model [7] which could potentially advance the ICF as a language of disability within a work-specific model. The Healthy Workplace model includes health promotion and injury prevention which are important aspects that support the use of the ICF beyond rehabilitation. Also, the ICF has been adopted as a reference for terminology and framework in the Guides to the Evaluation of Permanent Impairment of the American Medical Association [8].

The ICF has come a long way since its approval by the World Health Assembly in 2001. Nowadays, works on the ICF come from not just one part of the globe or from one particular health profession or industry. We are now seeing continuing and emerging studies and new evidence from around the world which are making an impact on how we assess health at the population level, forge collaboration between countries, implement sophisticated measurement methodologies, and improve clinical application and patient care [9-11]. These efforts clearly go beyond the mere conceptualization of the ICF. We believe that this trend will continue and that there will be more evidence to support the use of the ICF by way of innovative studies. In this special section of JOOR, we will demonstrate how the ICF was used as a centrepiece in conducting studies in VR.

\section{ICF and Vocational Rehabilitation: Order Despite Chaos}

We recognize that there are other models or frameworks that depict work disability and VR. It is the intention of the ICF as a generic model to work side-by-side amongst these other models i.e. serving a complementary role rather than to the exclusion of the others. For instance, given the generic feature of the ICF but with the possibility of specific application, it has been used and discussed in work-specific relevant areas such as job placement [12], legislation [13, 14], consumer participation [15], occupational intervention [16], workplace and mental health [17], vocational education [18], and social security [19]. The ICF can be made an integral component of an existing work-specific model [20]. So, there are studies that have used the guiding and generic principles of the ICF yet with impressive specific application.

\section{ICF Core Set for Vocational Rehabilitation: The Beginning}

In 2008, the ICF Research Branch in cooperation with the WHO Collaborating Centre for the Family of International Classifications in Germany (at DIMDI) embarked on a project to develop the ICF Core Set for Vocational Rehabilitation. This project is a collaboration and partnership with international organizations, research institutes, health 
care organizations, and VR experts. The project's Steering Committee included the Classification, Terminology and Standards Department of the World Health Organization (WHO-CTS), ILO, WCPT, WFOT, and ISPRM. In addition, a Local Advisory Group based in Switzerland and Germany has also been consulted. This group consisted of individuals from the study centers, VR agency representatives, and a patient (or client) advocacy group. Both the international Steering Committee and Local Advisory Group have been advised by international and national experts in the field of VR.

A protocol paper with the overview of the project was published in 2009 [2]. The project consisted of three sequential phases: (1) four development studies, (2) international consensus conference, and (3) testing and validation phase of the ICF Core Set. A discussion paper by Escorpizo and colleagues [21] on the conceptual definition of VR using the ICF is the first article in this special section, followed by four articles presenting the results from the first phase of the project [22-25]. Results from the second phase i.e. consensus conference is being reviewed separately elsewhere [26] and where future plans for the testing and validation of the Core Set for VR (which was developed during the consensus conference) are presented. A brief description of the five papers included in this special section is presented below.

\section{Defining Vocational Rehabilitation}

Escorpizo and colleagues from different WHO regions present arguments for conceptually defining VR based on the ICF [21]. The authors explored the available literature and relevant models in VR and explained their relation to disability, rehabilitation, and functioning. The article concluded with a conceptual definition of VR that can be widely applied in different settings and by different stakeholders. Their article discussed ways by which the ICF can be used alongside other work-specific models.

\section{ICF Core Set Development Studies}

The categories reflecting the domains of functioning contained in the ICF are simply too many that the practical application becomes difficult. Therefore, to make the use of the ICF feasible in clinical practice and in conducting research or trials, projects on developing a Core Set of ICF categories were initiated [27]. An ICF Core Set refers to a fraction of the ICF or a short list of ICF categories that are relevant to a specific health condition, health condition group, or health situation. Similar to other ICF Core Set projects in the past, the development process of our project involved three phases. The first phase consisted of preliminary studies from different perspectives: systematic review (literature perspective), expert survey (expert perspective), cross-sectional study (clinical perspective), and focus group interview (client perspective). Results of each study are presented in this special section.

\section{Literature Perspective}

Published literature can be a rich source of information to answer specific research questions. Escorpizo and colleagues, in their systematic review of the literature (250 studies), identified those ICF categories that have been used in the literature surveyed [22]. Measures (648 of them) used in those studies were linked to the ICF. Their study supports the diversity of VR and the multitude of measures that are used. Most of the ICF categories found in the measures were related to the activities and participation component of the ICF.

\section{Expert Perspective}

Escorpizo and colleagues conducted an international webbased survey. Experts from different WHO regions with diverse backgrounds in research, teaching, and practice were invited and randomly selected. The authors identified those ICF categories that experts in VR considered to be relevant and important [23]. The responses from 151 experts were then linked to the ICF. They found expertidentified domains that cut across multiple health conditions and health care settings. This finding is consistent with the first article on systematic review. The majority of the ICF categories, as revealed by the experts, were related to the activities and participation component of the ICF.

\section{Clinical Perspective}

Finger and colleagues performed a cross-sectional study of 152 patients attending VR programs in clinics [24]. Their article looked at those domains which were found to be problematic by clinical health professionals in patients in VR programs. Again, most of the ICF categories considered problematic among the patients were related to the activities and participation component of the ICF.

\section{Client (Consumer or Patient) Perspective}

Glässel and colleagues looked at the client perspective by conducting seven focus group interviews of clients undergoing VR in different clinics [25]. A wide variety of factors were identified by the clients as important in their care. Unlike the other studies, most of the ICF categories were found to be related to the body functions component of the ICF. 
Table 1 Distribution of ICF categories across ICF components and across studies

\begin{tabular}{|c|c|c|c|c|}
\hline & $\begin{array}{l}\text { Systematic } \\
\text { review [22] }\end{array}$ & $\begin{array}{l}\text { Expert } \\
\text { survey [23] }\end{array}$ & $\begin{array}{l}\text { Cross-sectional } \\
\text { study [24] }\end{array}$ & $\begin{array}{l}\text { Focus group } \\
\text { interview [25] }\end{array}$ \\
\hline Perspective & Literature & Experts & Clinicians & Clients \\
\hline \multicolumn{5}{|l|}{ ICF component } \\
\hline Body functions (b) & $31(35.6 \%)$ & $22(21.8 \%)$ & $24(24 \%)$ & $53(33.1 \%)$ \\
\hline Body structures (s) & - & $13(12.9 \%)$ & $6(6 \%)$ & $13(8.1 \%)$ \\
\hline Activities and participation (d) & $43(49.4 \%)$ & $36(35.6 \%)$ & $45(45 \%)$ & $51(31.9 \%)$ \\
\hline Environmental factors (e) & $13(14.9 \%)$ & $30(29.7 \%)$ & $25(25 \%)$ & $43(26.9 \%)$ \\
\hline Total number of categories & 87 & 101 & 100 & 160 \\
\hline
\end{tabular}

Numbers in bold represent the highest percentage

Body functions physiological functions of body systems including psychological functions. Body structures anatomical parts of the body such as organs, limbs, and their components. Activity execution of a task or action by an individual. Participation "involvement in a life situation. Environmental factors physical, social, and attitudinal environment in which people live and conduct their lives [3]

A summary of the findings of the different studies is presented in Table 1.

\section{Conclusion}

In this special section, we have presented five articles in an effort to advance our understanding and measurement of VR and the RTW process. We believe that by doing so, we are addressing critical issues that need attention in the work disability field. This special section also highlights the complexity of the contents of VR and presents opportunity on how we can operationalize the ICF in actual VR settings. We have discussed why it is vital to have a common conceptual understanding of VR that will, in turn, benefit patient care and scientific research. The newly developed ICF Core Set for VR is informed by different perspectives: published literature, experts, clinicians, and clients. Our findings were diverse and the message is clear: we can gain an important insight from the findings of the different studies that would advance the field of VR.

The distribution of ICF categories across components and across studies provided us with interesting information on the current state of the field. Activities and participation represent most of the ICF categories from all studies except for the client perspective where body functions (followed closely by activities and participation) were predominant. While this might be an encouraging finding, knowing that domains in the wider context of activities and participation are essential, our studies also identified that there is a pronounced disparity concerning the lack of proportional representation of the environmental factors which, as a contextual factor, can play a major role in facilitating work participation.

Our findings reflect the wide range of factors that could influence success (or failure) in VR. ICF-based domains were used in the reporting of these factors which we believe make them compatible with other existing works where ICF has also been used and where the ICF was the language of reference to describe functioning and disability.

We recognize the criticisms of using the ICF specifically in VR and in addressing work disability issues, particularly around psychometric validation and clinical utility of the ICF codes. However, we would argue that we need to start somewhere and we do not see any reason to forestall exploring the use of the ICF to examine and measure VR processes and outcomes. The ICF is a reasonable starting point in our effort to harmonize terminologies and conceptual frameworks in VR. While the ICF is only a decade old, it has already garnered the support of multiple stakeholders across disciplines and countries. We invite the whole VR community to continue to dialogue and foster collaboration so we can all take advantage of what the ICF can offer. We believe that our common goals of facilitating work participation, early and sustained RTW, and improved work productivity are what thread us all together. We also value information from other stakeholders such as employers and the social security and insurance system, and thus, foresee a progressive research agenda on that end.

Acknowledgments We would like to thank the Steering Committee members: Nenad Kostanjsek (WHO), Barbara Murray (ILO), Catherine Sykes (WCPT), Marilyn Pattison (WFOT), Alessandro Giustini, and Jan Ekholm (ISPRM); the Local Advisory Group: Peter Erhart, Ulrike Hoffmann-Richter, Stefan Ritler, Kurt Gfeller, Cornelia Bachofner, Carl Gennheimer, Olivier Deriaz, Gilles Rivier, Franco Lanfranchi, Andreas Klipstein, Hans-Martin Schian, and Christian Wenk. We would like to acknowledge Melissa Selb and Monika Finger from the ICF Research Branch, and Brittany Norton for their review of this manuscript prior to submission. Special thanks to JOOR Chief Editor Michael Feuerstein and Managing Editor Patricia A. Findley for the great opportunity to be able to contribute to the advancement of the field of vocational rehabilitation. The Swiss Accident Insurance of Switzerland (Suva) funded the project. 


\section{References}

1. Collie J. Return to work-legal and other impediments. Br Med J. 1916;2:757-9.

2. Escorpizo R, Ekholm J, Gmuender HP, Cieza A, Kostanjsek N, Stucki G. Developing a Core Set to describe functioning in vocational rehabilitation using the International Classification of Functioning, Disability, and Health (ICF). J Occup Rehabil. 2010;20(4):502-11.

3. World Health Organization. International Classification of Functioning, Disability and Health: ICF. Geneva: WHO; 2001.

4. International Labour Organization. About the ILO. Mission and objectives. Available from: http://www.ilo.org/global/about-theilo/mission-and-objectives/lang-en/index.htm. 2011.

5. Ustun TB, Chatterji S, Bickenbach J, Kostanjsek N, Schneider M. The International Classification of Functioning, Disability and Health: a new tool for understanding disability and health. Disabil Rehabil. 2003;25(11-12):565-71.

6. International Labour Organization. Statistics on the employment situation of people with disabilities: a compendium of national methodologies. 2003; Available from: http://www.ilo.org/public/ english/bureau/stat/download/papers/disable.pdf. 2011.

7. World Health Organization. Launching healthy workplaces: a global model for action on the occasion of the World Day for Health and Safety at Work. 2011; Available from: http://www. who.int/occupational_health/healthy_workplaces/en/. 2011.

8. Rondinelli RD, Genovese E, Katz RT, et al., editors. Guides to the evaluation of permanent impairment. 6th ed. Chicago: American Medical Association; 2009.

9. Raggi A, Leonardi M, Cabello M, Bickenbach JE. Application of ICF in clinical settings across Europe. Disabil Rehabil. 2010;32: $17-22$.

10. Peterson DB. Psychological aspects of functioning, disability, and health. New York: Springer Publishing Company; 2011.

11. Mpofu E, Oakland T, editors. Rehabilitation and health assessment: applying ICF guidelines. New York: Springer Publishing Company; 2010.

12. Homa DB. Using the International Classification of Functioning, Disability and Health (ICF) in job placement. Work. 2007;29(4): 277-86.

13. Okawa Y, Ueda S, Shuto K. The utilization of ICF in National Legislation and Policies in Japan. WHO-FIC NETWORK MEETING; 2005:16-22 October.

14. Conclave M, Fusaro G, Sala M, Martinuzzi A, Russo E, Frare M, et al. The ICF and labour policies project: the first Italian nationwide experience of ICF implementation in the Labour Sector. Disabil Rehabil. 2009;31:16-21.
15. Shaw L, Leyshon R, Liu M. Validating the potential of the International Classification of Functioning, Disability and Health to identify barriers to and facilitators of consumer participation. Can J Occup Ther. 2007;74:255-66.

16. Leyshon RT, Shaw LE. Using the ICF as a conceptual framework to guide ergonomic intervention in occupational rehabilitation. Work. 2008;31(1):47-61.

17. Sanderson K, Nicholson J, Graves N, Tilse E, Oldenburg B. Mental health in the workplace: using the ICF to model the prospective associations between symptoms, activities, participation and environmental factors. Disabil Rehabil. 2008;30(17):1289-97.

18. Chamberlain MA, Fialka Moser V, Schuldt Ekholm K, O'Connor RJ, Herceg M, Ekholm J. Vocational rehabilitation: an educational review. J Rehabil Med. 2009;41(11):856-69.

19. Brage S, Donceel P, Falez F. Development of ICF core set for disability evaluation in social security. Disabil Rehabil. 2008; 30(18):1392-6

20. Sandqvist JL, Henriksson CM. Work functioning: a conceptual framework. Work. 2004;23(2):147-57.

21. Escorpizo R, Reneman MF, Ekholm J, Fritz J, Krupa T, Marnetoft SU, et al. A conceptual definition of vocational rehabilitation based on the ICF: building a shared global model. J Occup Rehabil. 2011; Feb 12 (in press).

22. Escorpizo R, Finger ME, Glässel A, Gradinger F, Lückenkemper M, Cieza A. A systematic review of functioning in vocational rehabilitation using the International Classification of Functioning, Disability and Health (ICF). J Occup Rehabil. 2011; Feb 12 (in press).

23. Escorpizo R, Finger ME, Glässel A, Cieza A. An international expert survey on functioning in vocational rehabilitation using the International Classification of Functioning, Disability and Health. J Occup Rehabil. 2010; Dec 9 (in press).

24. Finger ME, Glässel A, Gmünder HP, Stucki G, Gradinger F, Klipstein A, et al. Identification of relevant ICF categories in vocational rehabilitation - a cross-sectional study evaluating the clinical perspective. J Occup Rehabil (in press).

25. Glässel A, Finger ME, Cieza A, Treitler C, Coenen M, Escorpizo R. Vocational rehabilitation from the client's perspective using the International Classification of Functioning, Disability and Health (ICF) as a Reference. J Occup Rehabil. 2011; Jan 22 (in press).

26. Finger ME, Escorpizo R, Glässel A, Gmünder HP, Lückenkemper M, Chan C, et al. ICF Core Set for vocational rehabilitation: results of an international consensus exercise. Disabil Rehabil (under review).

27. Cieza A, Ewert T, Üstün B, Chatterji S, Kostanjsek N, Stucki G. Development of ICF Core Sets for patients with chronic conditions. J Rehabil Med. 2004;36(44):9-11. 